\title{
Retroflexion in the duodenal bulb combined with tunnel and double-clip traction: the key to successful endoscopic submucosal dissection of a malignant gastric adenoma protruding through the pylorus
}

An 81-year-old man was referred for resection of a prepyloric lesion, described as a large pseudopolypoid gastric fold, with low grade dysplasia adenoma on biopsies. Examination showed a flat, centrally depressed lesion without ulceration, protruding completely through the pylorus ( Video $\mathbf{1}$ ). The distal side of the lesion could not be assessed in forward view, despite the use of a transparent cap. A careful retroflexion in the bulb, with underwater examination (gastroscope GIF-H190; Olympus, Tokyo, Japan), allowed perfect visualization of the distal margin ( Fig.1 a). After submucosal injection of glycerol solution with indigo carmine, distal incision was carefully made in retroflexion in the duodenum, with a DualKnife J $1.5 \mathrm{~mm}$ (Olympus)

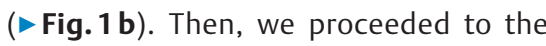
proximal incision and submucosal dissection in a tunnel with visualization of the pylorus muscle arch (\$Fig. 1 c). Countertraction was applied with two clips (Resolution $360^{\circ}$; Boston Scientific, Marlborough, Massachusetts, USA) and rubber band to expose the posterior edges ( $\triangleright$ Fig.1d). During the procedure, the axis of the counter-traction was modified to allow good exposure of the superior and anterior parts of the lesion. En bloc resection was achieved ( $\mathbf{F i g} \mathbf{2} \mathbf{2}$ ). Histological examination confirmed complete resection of intestinal-type pyloric adenoma with intramucosal adenocarcinoma ( Fig. 2 b) .

Retroflexion can be useful for endoscopic submucosal dissection (ESD) and is widely used in the stomach, rectum, and colon. Although retroflexion can be considered tricky and risky in the duodenum, it was the only way to ensure correct management of the distal edge of this lesion. To our knowledge, duodenal retroflexion to achieve ESD of pyloric lesions has been studied in only two case series, with no complications reported [1,2], and seems

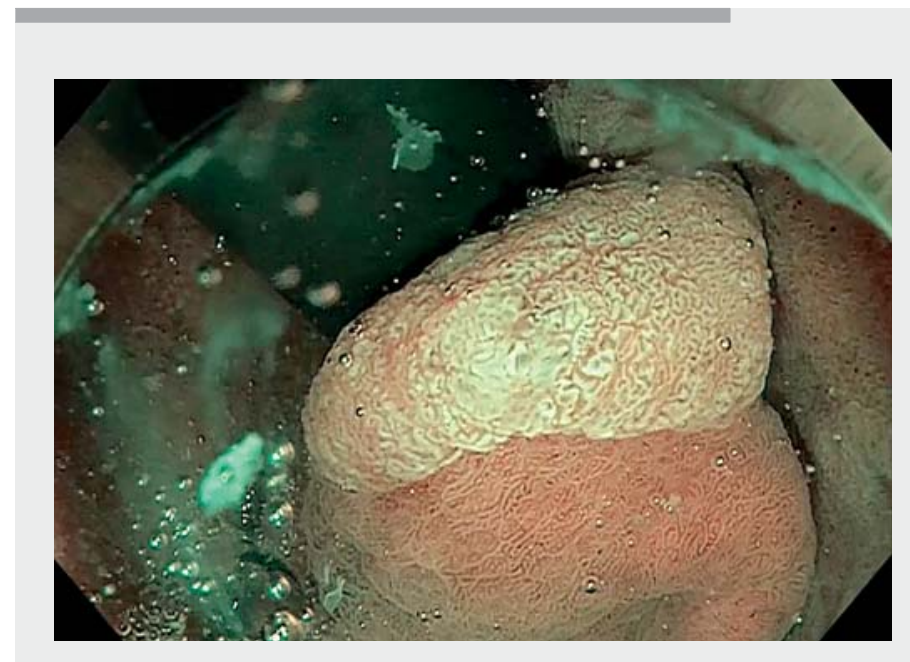

Video 1 Retroflexion in the duodenal bulb combined with tunnel and double-clip traction: the key to a successful endoscopic submucosal dissection of a gastric adenoma protruding through the pylorus.
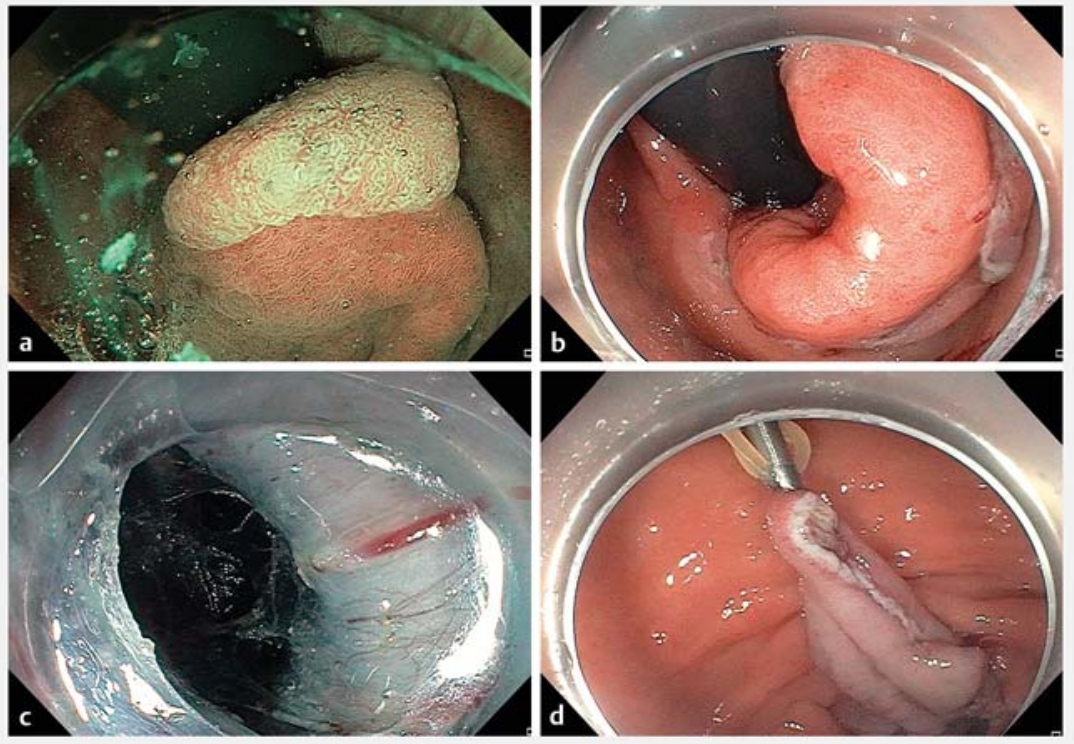

Fig. 1 Endoscopic submucosal dissection procedure with combined strategy: retroflexed incision, tunnel through the pylorus, and clip-traction assistance. a Distal evaluation of the lesion in duodenal bulb retroflexion. $\mathbf{b}$ Distal incision of the tunnel in retroflexion. $\mathbf{c}$ Tunnel dissection with pyloric arch visible in the tunnel. $\mathbf{d}$ Double-clip and rubber-band countertraction. 

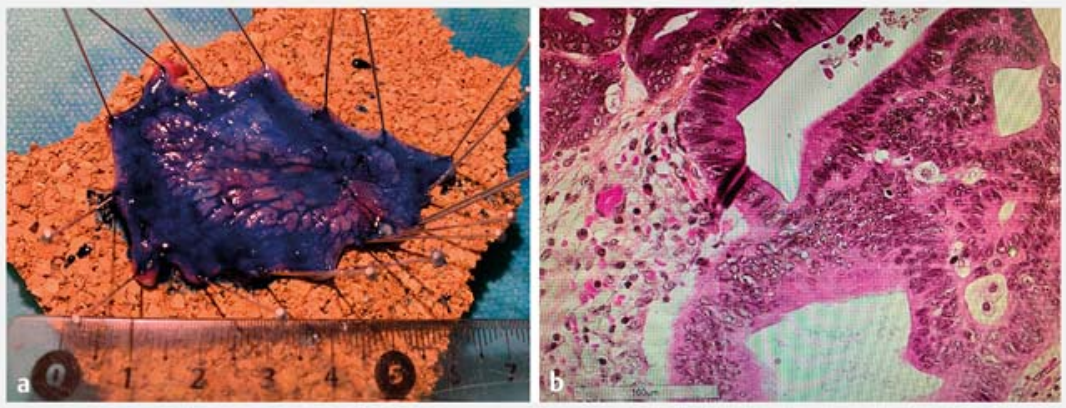

- Fig. 2 Resected specimen and histology result. a Specimen. $\mathbf{b}$ Histological aspect of the intramucosal adenocarcinoma on pyloric adenoma (hematoxylin and eosin stain).

to increase en bloc resection rates. Combining retroflexion with the easy-to-use and changeable counter-traction with double clips and rubber band [3] could make the resection of these challenging lesions feasible.

Endoscopy_UCTN_Code_TTT_1AO_2AG

Competing interests

The authors declare that they have no conflict of interest.

The authors

Marion Schaefer ${ }^{1}$, Thomas Lambin ${ }^{2}$, Benjamin $\mathrm{Hamel}^{3}$, Clémentine Gandilhon ${ }^{4}$, Jérémie Jacques $^{5}$, Jérôme Rivory ${ }^{2}$, Mathieu Pioche ${ }^{2}$

1 Service d'Hépato-gastro-entérologie, CHRU de Nancy, Vandoeuvre-les-Nancy, France

2 Service d'Hépato-gastroentérologie, Hôpital Edouard Herriot, Lyon, France
3 Service d'Hépato-gastroentérologie, Hôpital Nord Ouest, Villefranche-Sur-Saône, France

4 Cabinet de Médecine Générale, PontcharraSur-Turdine, France

5 Service d'Hépato-gastroentérologie, $\mathrm{CHU}$ Dupuytren, Limoges, France

\section{Corresponding author}

\section{Marion Schaefer, MD}

Hépato-gastroentérologie, CHRU de Nancy Hôpital Brabois Adultes, 54511 Vandoeuvre Les Nancy, France

m.schaefer@chru-nancy.fr

\section{References}

[1] Lim C-H, Park JM, Park C-H et al. Endoscopic submucosal dissection of gastric neoplasia involving the pyloric channel by retroflexion in the duodenum. Dig Dis Sci 2012; 57: 148154

[2] Park JC, Kim J-H, Youn YH et al. How to manage pyloric tumours that are difficult to resect completely with endoscopic resection: comparison of the retroflexion vs. forward view technique. Dig Liver Dis 2011; 43: 958-964

[3] Jacques ], Charissoux A, Legros R et al. Double-clip counter-traction using a rubber band is a useful and adaptive tool for colonic endoscopic submucosal dissection. Endoscopy 2018; 50: 179-181

Bibliography

Endoscopy 2022; 54: E245-E246

DOI 10.1055/a-1492-2214

ISSN 0013-726X

published online 8.6.2021

(c) 2021. Thieme. All rights reserved.

Georg Thieme Verlag KG, Rüdigerstraße 14,

70469 Stuttgart, Germany

\section{ENDOSCOPY E-VIDEOS}

https://eref.thieme.de/e-videos

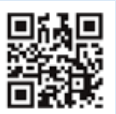

Endoscopy E-Videos is an open access online section, reporting on interesting cases and new techniques in gastroenterological endoscopy. All papers include a high quality video and all contributions are freely accessible online. Processing charges apply (currently EUR 375), discounts and wavers acc. to HINARI are available.

This section has its own submission website at

https://mc.manuscriptcentral.com/e-videos 